\title{
Espacio escolar y género. El caso del Departamento de Cultura Física de la Universidad Nacional de La Plata $(1929-1946)^{1}$
}

School space and gender. The case of the Department of Physical Culture of the Universidad Nacional de La Plata (1929-1946)

Recepción: 23 Mayo 2020 Aprobación: 08 Septiembre 2020 Publicación: 09 Octubre 2020

Cita sugerida: Kopelovich, P. (2020). Espacio escolar y género. El caso del Departamento de Cultura Física de la Universidad Nacional de La Plata (1929-1946). Educación Física y Ciencia, 22(4), e146. https:// doi.org/10.24215/23142561e146
Pablo Kopelovich

kopelovichp@gmail.com

Instituto de Investigaciones en Humanidades y Ciencias Sociales -Universidad Nacional de La Plata (IdIHCS - UNLP), Argentina
Resumen: El objetivo de este artículo es analizar el uso de espacios diferenciados para la práctica de ejercicios físicos entre 1929 y 1946, a cargo del Departamento de Cultura Física (DCF), por parte de los estudiantes varones del Colegio Nacional (CN) y estudiantes mujeres del Colegio Secundario de Señoritas (CSS), instituciones de enseñanza media de la Universidad Nacional de La Plata (UNLP). A partir de una metodología cualitativa se lleva a cabo un estudio de caso, utilizando variadas fuentes. Se encuentra que los varones ocuparon lugares abiertos, grandes, en el ámbito natural, con buenas condiciones edilicias, mientras que las mujeres lo hicieron en espacios cerrados, pequeños, dentro del colegio, con problemas edilicios. Concluimos que los espacios diferenciados contribuyeron a vincular a las mujeres al ámbito privado, y a actividades pasivas, estableciendo fines macropolíticos ligados a ser madre, y a relacionar a los hombres con el espacio público, emparentándolos con actividades que implicaban mayor actividad, responsabilidad y autonomía. El espacio fue parte de un currículum que sexualizó y generizó, estableciendo universos morales y kinéticos desiguales.

Palabras clave: Espacio escolar, Género, Historia, Departamento de Cultura Física, Universidad Nacional de La Plata.

\begin{abstract}
The objective of this article is to analyze the use of differentiated spaces for practicing physical exercises between 1929 and 1946, by the Department of Physical Culture, by male students from the Colegio Nacional and female students from the Colegio Secundario de Señoritas, both high schools part of the Universidad Nacional de La Plata. From a qualitative methodology, a case study is carried out using various sources. It is found that men occupied large, open spaces in the natural environment, with good building conditions, while women did so in small, closed spaces, inside the school, with building problems. We conclude that differentiated spaces contributed to linking women to the private sphere and to passive activities, establishing macropolitical aims linked to being a mother, and relating men to the public space; thus, to activities that implied greater activity, responsibility and autonomy. The space was part of a curriculum that sexualized and gendered, establishing unequal moral and kinetic universes.
\end{abstract}

Keywords: School space, Gender, History, Departamento de Cultura Física, Universidad Nacional de La Plata. 


\section{Introducción}

En enero de 1929, en el marco del debate sobre la modificación de los planes de estudio del CN y el CSS (las dos instituciones de enseñanza media de la UNLP de ese momento), el presidente de esa casa de estudio planteó la creación de un Departamento de Cultura Física. Ello se concretó el 7 de marzo del mismo año. Allí, Loyarte ${ }^{2}$, a propuesta del rector del CN, Rafael Arrieta ${ }^{3}$, nombró como Director al profesor de gimnasia Benigno Rodríguez Jurado ${ }^{4}$, que se desempeñaba en el CN desde 1926. Se presentó como "el primer organismo de esta índole dependiente de una Universidad en la República Argentina (...)” (Rodríguez Jurado, 1929, p. 26), destacándose que contaba con la segunda pileta de natación más grande del país (Rodríguez Jurado, 1929). Finalmente, se encargó de organizar la Educación Física obligatoria de la escuela graduada "Joaquín V. González" y los dos colegios de enseñanza media, a la vez que ofrecer cursos voluntarios para alumnos de las diferentes Facultades de la UNLP. El surgimiento del DCF se produjo, entonces, en un marco de políticas de la UNLP que, con Ramón Loyarte al frente, tendieron al restablecimiento del orden y de la disciplina académicas, perdidos en el marco del movimiento de la Reforma Universitaria (Belinche y Panella, 2014).

El campo de deportes, inicialmente, entre 1910 y 1920, había estado en manos de los Internados del CN, identificados por el movimiento Reformista como el símbolo de una universidad de privilegio, por ser oneroso y aplicado solo a un selecto grupo de estudiantes secundarios (Gentile y Vallejo, 1999). Luego, pasó a estar en manos de la Casa del Estudiante (1921-1923), tratándose de un emprendimiento pensado para todos, que adoptó el ejemplo de la Residencia de Estudiantes en Madrid, en tanto centro para el desarrollo de diversas experiencias sociales y artísticas (Vallejo, 2018). En la gestión de Nazar Anchorena (1921-1927), a partir de una serie de incidentes no del todo aclarados, identificados por las autoridades, se cedieron los antiguos edificios de los Internados a las nuevas Facultades (Físico-matemática, Química y Farmacia), en un marco de una progresiva declinación de las conquistas reformistas en la UNLP (Gentile y Vallejo, 1999). El DCF se habría creado para recuperar, entonces, definitivamente, las riendas de ese sector. En este sentido, son elocuentes las referencias de Benigno Rodríguez Jurado a que el DCF surgió para disciplinar el carácter y la inteligencia (Rodríguez Jurado, 1929) y la alusión a que debe dirigir y vigilar el desarrollo físico de los niños y los jóvenes (Rodríguez Jurado, 1929). Los inicios del DCF tuvieron como marco nacional la denominada década infame o restauración conservadora (Romero, 1995; Reitano, 2005; Cattaruzza, 2009), que incluyó fraude, violencia, coerción e intimidación contra la oposición (Scharagrodsky, 2006a), ampliándose en ese período marcadamente la injerencia del Estado sobre la sociedad (Pinkasz y Pitelli, 1997), siendo la Iglesia católica la institución que más decididamente acompañó su gestión (Bejar, 2005). Entre 1936 y 1940, en la provincia de Buenos Aires, estuvo 
al frente de la gobernación Manuel Fresco, considerado como el mayor avance de las teorías fascistas (declarado admirador de Hitler, Franco y Mussolini) y corporativistas en nuestro país. Una de las modificaciones más importantes implementadas en la provincia por este gobernador se vinculó al ámbito educativo, con la reforma Fresco-Noble, que se opuso al excesivo intelectualismo, verbalismo y enciclopedismo identificados, y a la carencia de valores morales y patrióticos que guíen la acción escolar (Pineau, 1999).

El CN y el CSS preparaban especialmente para el ingreso a la Universidad, recibiendo estudiantes de sectores medios y altos de la sociedad (Di Piero, 2018) y nacieron con la misión de seleccionar un fragmento de la sociedad digno de convertirse en el sector dirigencial o pertenecientes a una elite (Legarralde, 1999). Los colegios nacionales, creados en el marco de la política educativa del gobierno de Bartolomé Mitre (presidente de la Nación entre 1862 y 1868), tenían como referencia al de Buenos Aires, que se orientaba sobre los ejes de las Humanidades y la Filosofía, con una intención de formación holística (Legarralde, 1999), enciclopedista (Tedesco, 1993). Inés Dussel (1997), que abarca el período 1863-1920, caracteriza al currículum de los colegios nacionales como "humanista clásico" que luego evoluciona hacia un currículum de "humanidades modernas".

El DCF tomó como central el discurso médico, en detrimento del pedagógico, que incluyó el anatómico, el fisiológico, y, especialmente, el eugenésico. Asimismo, tomó elementos del discurso militarista, a la vez que propuso prácticas corporales diferenciadas genéricamente, vinculadas a la gimnasia, el juego y, de forma temprana para la época, al deporte. El 11 de octubre del año 1946, la Intervención de la UNLP con Orestes Adorni a la cabeza, por decreto $4034 / 22$, creó, en reemplazo del DCF, la Dirección General de Educación Física de la UNLP, conformándose a ese efecto una comisión integrada por el Dr Juan José Pimentel (Secretario Privado del Interventor en la Universidad), Dr. Ángel T. Albina (Jefe Médico del Departamento), Teresa Blasi (profesora de Educación Física del CSS), Capitán Alejandro Amavet (profesor de Educación Física) y el Dr. Osvaldo J. Rumbo (odontólogo del CN) (Universidad Nacional de La Plata, 1947) ${ }^{5}$.

En lo que respecta a nuestra disciplina, se encontraba en un momento de conformación de la matriz disciplinar de la Educación Física como asignatura escolar (Aisenstein, 2008). Los componentes que entraron en juego, a través de diversas articulaciones, en la conformación de la asignatura pueden identificarse con tres ámbitos de procedencia: a) el campo cultural de las actividades físicas y deportivas, b) el campo de las ciencias biológicas, sociales y de la salud, y c) el campo pedagógico (Aisenstein, 2006). Así, la asignatura Educación Física contribuyó a controlar y educar los cuerpos de una forma higiénica, patriótica, acorde al género de los alumnos, disciplinada, moralmente correcta, saludable, bella, productiva, racional, científica (Scharagrodsky, 2011), llevándose a cabo en concordancia con intenciones macropolíticas, como la formación de un ciudadano libre para la búsqueda del progreso, y a las 
necesidades vinculadas con la organización nacional (Aisenstein, 2006). En ese momento predominaban dos formas de entender la formación: la militarista y la "romerista" (Scharagrodsky, 2011), que entendieron de diferente modo ciertas cuestiones como el sujeto, el cuerpo y la política, entre otras cosas (Galak, 2012).

Nos proponemos, entonces, analizar, de forma relacional, los espacios utilizados para la enseñanza secundaria en el CSS y en el CN, en lo que respecta a la cultura física y la cultura física femenina y de qué modo estos espacios, desde una educación diferenciada, generizaron y sexualizaron. El período abordado va desde 1929, momento de conformación del DCF, a 1946, momento de su reemplazo por la Dirección General de Educación Física de la UNLP.

\section{Estrategia metodológica y herramientas teórico- epistemológicas}

El trabajo se desarrolló sobre la base de una estrategia metodológica cualitativa o no estándar. Se propuso la interpretación de un caso para comprender la particularidad del objeto y no porque el DCF represente otros casos o ilustre una característica particular del problema, sino que, debido a su naturaleza e historia particular, nos resulta en sí mismo de interés. Los estudios de casos muy delimitados en términos geográficos y temporales, pero insertos en un contexto teórico e histórico mucho más amplio, permiten articular en un nivel de conjunto los niveles micro y macro. Así, se permite vincular lo individual y lo social, los procesos globales y las experiencias específicas de distintos actores sociales (Molina Jiménez, 1996). No se estudia el caso porque represente a otros, o porque ilustre algún rasgo, sino porque es interesante en sí mismo (Stake, 2005). La generación de información se desprendió de la utilización de una técnica de recolección de datos: el análisis de documentos (Sautu, Boniolo, Dalle y Elbert, 2005). Se propuso, así, una recolección flexible de la información. Es decir, un proceso interactivo continuo, marcado por el desarrollo de la investigación. Asimismo, fue central demarcar/construir claramente el contexto o "clima de época" de la cultura física en general y de la enseñanza de la Educación Física en clave de género en la provincia de Buenos Aires y en el país. Se buscó, siguiendo a Tarrés (2013, p. 6), "comprender a los sujetos sexuados en la historicidad de su tiempo".

Las principales fuentes primarias consideradas fueron: Planes y programas del CN y el CSS; Memorias anuales, normativas, reglamentos internos, actas, de dichas instituciones educativas; Fotografías de clases de gimnasia, de exhibiciones, de competencias deportivas, entre otras instancias registradas; Actas del Consejo Superior de la Universidad Nacional de La Plata entre 1929 y 1946; Legajos de profesores/as de la asignatura en cuestión y de los directivos de los colegios durante el lapso analizado; Artículos periodísticos sobre las instituciones escolares, las exhibiciones, las competencias deportivas, incidentes, sumarios realizados a docentes, cambio de autoridades, entre otros; Informes del director del DCF de la UNLP dirigidos al presidente de esta casa de estudios; Informes 
escritos por el director del DCF de la UNLP incluidos en boletines del CN y de la UNLP. Además, fueron entrevistadas tres exalumnas del CSS. Se construyeron las siguientes categorías: la naturaleza versus la cultura y los espacios escolares diferenciados para la práctica de ejercicios físicos.

Siguiendo a Judith Butler (2006), entendemos al género como el aparato o mecanismo mediante el cual tienen lugar la producción, normalización y naturalización de lo masculino y lo femenino. No siempre se constituye de forma coherente o consistente en contextos históricos distintos, entrecruzándose con modalidades raciales, de clase, étnicas, sexuales y regionales de identidades discursivamente constituidas. Así, es imposible separar el género de las intersecciones políticas y culturales en las que constantemente se produce y mantiene (Butler, 2018). En este sentido, la investigación, reflexión y debate alrededor de este ha conducido a plantear que las mujeres y los hombres no tienen esencias que se deriven de la biología, sino que son construcciones simbólicas pertenecientes al orden del lenguaje y de las representaciones. En cada cultura, una operación simbólica básica otorga cierto significado a los cuerpos de las mujeres y de los hombres. De este modo, mujeres y hombres no son un reflejo de la realidad "natural", sino que son el resultado de una producción histórica y cultural (Lamas, 2000). Adherimos a una visión relacional del género, para considerar "el aspecto dinámico y explicativo de la construcción de las identidades genéricas, de la feminidad y masculinidad como productos históricos." (Díaz Villa y Ortmann, 2011, s/p).

En relación a la masculinidad, es posible pensarla como la forma aprobada de ser varón en una sociedad determinada (Gilmore, 1990). Los estudios sobre la identidad masculina, en especial los estudios sociológicos y antropológicos de orientación feminista, han destacado la idea de que la masculinidad no es una esencia innata ni un hecho tan sólo biológico sino también, y, sobre todo, una construcción cultural. Es decir, el efecto en cada hombre, en cada época y en cada sociedad de un conjunto de creencias, conductas, normas y estilos de vida que otorgan a la mayoría de los hombres una serie de privilegios simbólicos y materiales por el sólo hecho de haber nacido hombres y de no ser mujeres (Lomas, 2014). La masculinidad debe identificarse dentro de un contexto social y unas prácticas sociales concretas, siendo la forma como las sociedades interpretan y usan los cuerpos masculinos (Connell, 2001). Además, pensando en "emblemas masculinos", se espera que los hombres sean procreadores (se tiene la expectativa de que el hombre desparrame su semilla), proveedores (que aporte el ingreso principal) y protectores (enfrentar peligros, involucrarse en conflictos) (Burin y Meler, 2009). Scharagrodsky (2007) plantea que los patrones y estilos de masculinidades presentan aspectos fuertemente interrelacionados: la masculinidad asociada a la heterosexualidad y a cierta jerarquización del cuerpo del varón, definida por oposición a la feminidad, y considerada como un organizador de la homofobia. En la misma línea van los planteos que consideran que la subjetividad masculina se construye desde pequeños alejándose de la madre (como lugar de origen) y que deberá afianzarse en 
tres pilares: no ser una mujer, no ser un bebé y no ser homosexual (Burin y Meler, 2009).

Con respecto a la feminidad, Simone de Beauvoir (1949) afirmó que "no se nace mujer, se llega a serlo" para indicar que la biología no es destino, que la sociedad establece todo un programa de vida para que un sujeto se transforme en mujer. De esta manera, “(...) la condición de la mujer está construida socialmente y determinada históricamente por el medio social" (Knecher y Panaia, 1994, p. 12; en Valobra, 2010, p. 87). La feminidad, entendida como un ideal regulativo históricamente situado, estuvo atravesada a lo largo de la historia por diferentes prácticas y saberes que la constituyeron (Scharagrodsky, 2006). La masculinidad dominante o hegemónica, por ejemplo, plantea que la calle es el lugar de los hombres, y que la casa es el lugar de las mujeres y de los/as niños/as, es un espacio femenino (Fuller, 1997; Gilmore, 1994; en Olavarría, 2004). Así, "ella es la responsable de la vida dentro del hogar y de la reproducción, debe cuidar el espacio del hogar y la crianza de los hijos; es emocional y expresa sus sentimientos; así lo hace con su pareja e hijos/as" (Olavarría, 2004, p. 50). Se trata de una consideración de la mujer como complemento del hombre.

La construcción de los cuerpos da origen a recursos de poder que se distribuyen inequitativamente entre hombre y mujeres. Se piensa a los cuerpos de los hombres como activos, duros, fuertes, aptos para el trabajo, la guerra y el mando, mientras que los cuerpos de las mujeres deben ser pasivos, delicados, débiles, aptos para trabajos livianos, cuerpos emocionales, para ser penetrados por los hombres y para la maternidad, cuerpos del hogar que hay que proteger: cuerpos complementarios a los de los hombres (Olavarría, 2004). Las feministas de diversas tradiciones, sostienen que la actitud pasiva femenina es una imposición cultural falogocéntrica, en vez de una condición constitucionalmente dada, siendo las mujeres impulsadas culturalmente a ubicarse en el lugar del objeto del deseo y de la pasividad (Martínez-Herrera, 2007). Puesto que no existe una feminidad esencial, la cultura construye modelos ideales, articulados con las relaciones sociales de desigualdad y poder entre los sexo-géneros, con los que las mujeres se identifican e incorporan a su Ideal del Yo (Tubert, 2010).

Asimismo, el currículum escolar influye fuertemente en las nociones de cuerpo, género y sexualidad que se transmiten, dejando importantes marcas en los educandos en la configuración de sus modos de entender el mundo en términos de estereotipos, funciones, sensibilidades, de roles masculinos y femeninos, y de maneras correctas e incorrectas (normales y anormales, fomentadas y prohibidas, saludable y nocivas) de utilizar el cuerpo de manera diferenciada. Toda educación es sexual, afirma Morgade (2011), por lo que el currículum generiza y sexualiza. Entonces, se construye un orden corporal, y un universo posible e imposible de movimientos, gestos, actitudes corporales, que es apropiado, y resistido, discutido, tensionado, por los y las estudiantes. En este sentido, 
Sin embargo, el orden corporal escolar no es cualquier (des)orden. Lleva implícito ciertas reglas, ciertas prácticas y ciertos saberes (Scharagrodsky, 2001, p. 79).

Optamos por finalizar este apartado haciendo una breve referencia teórica sobre la ciudad, el espacio, el espacio escolar y el vínculo entre este último y el género. El entorno no es meramente el escenario donde se inscribe la interacción social, sino que es considerado un elemento de esa interacción (Valera, 1999), por lo que es posible entender al espacio como una construcción social, cultural, estética y política, históricamente situada (Lefebvre, 2013; Massey, 2005; Casey, 1996; Scharagrodsky, 2019). En ese sentido, los espacios no solo son pensados como social y culturalmente construidos, sino también como productores de diversos sentidos, muchos de ellos ambiguos, contradictorios, paradójicos y ambivalentes (Scharagrodsky, 2019), ya que

los lugares fueron no solo soporte 'material' con ciertas formas y funciones, sino también condensaron en su propia constitución representaciones, metáforas, metonimias, evocaciones, sentidos y significados sociales, culturales, ideológicos, morales, sexuales, estéticos, éticos y políticos (Scharagrodsky, 2019, p.75).

En lo que respecta al ámbito educativo, se considera a la arquitectura y el espacio escolar como dos categorías implicadas en la configuración histórica de la escuela como una institución socio-cultural con una identidad propia (relativamente autónoma) (Ortega Ibarra y Dussel, 2019). De este modo, la arquitectura escolar se trataría en su propia expresividad, de una mediación pedagógica, un programa educador (Escolano Benito, 2000). Tanto el espacio, como el tiempo, son elementos básicos, constitutivos de la actividad educativa; por lo que estos socializan y educan (Viñao Frago, 1993-1994). El espacio condiciona -facilita y dificulta, posibilita e imposibilita- las interacciones, líneas y modos de comunicación (Viñao Frago, 2008). De este modo, "la forma cómo se agrupan los edificios; la relación entre actividades y espacios abiertos y cerrados; la relación centro-periferia y sus formas de inclusión-exclusión, nos dice algo sobre la configuración social” (Del Valle, 1995, p. 225). Es decir, la utilización del espacio en el ámbito educativo es uno de los modos posibles de deducir los lugares ocupados por las ciudadanas y los ciudadanos en cierta sociedad en determinado momento histórico. En ese sentido, "la distribución del espacio en los centros educativos forma parte del currículum oculto de los mismos y las referencias al género en la distribución del mismo así lo demuestran" (Cantón Mayo, 2007, p. 115). Implícitamente, se transmiten ciertos mensajes a través del espacio, se educa, en el caso que nos compete, de forma diferencial. En esta línea, es central el vínculo entre el edificio escolar y la ciudad, porque esta no es el contexto del proceso educativo, ni un escenario más, sino una variable que tiene la misma importancia que los edificios escolares (Piccato, 2001; Leinderberger, 2004; Barbosa, 2008; Chaoul Pereyra, 2019). Por ello, es fundamental el diálogo entre los edificios escolares y el espacio urbano, ya que

cuando incorporamos la variable urbana, no estamos considerando a la institución escolar como una institución aislada sino como un fenómeno social que se explica 
a partir de una multiplicidad de procesos relacionados, como la afluencia que ha tenido el propio dinamismo de la urbanización en el desarrollo material de las escuelas, en los actores y en el devenir de los modelos pedagógicos (Chaoul Pereyra, 2019, p. 14).

Así, las formas físicas no aportan solo un dato complementario, sino que sugieren preguntas de las que pueden derivar nuevas formas de entender la historia (Vallejo, 2007). Y en lo que respecta al vínculo con los cuerpos, "cuerpo y ciudad se configuran mutuamente y, además de los cuerpos estar inscriptos en las ciudades, las ciudades también quedan inscriptas y configuran nuestros cuerpos" (Britto y Jacques, 2012, p. 144; traducción personal).

\section{Resultados y discusión}

El campo de deportes en el bosque platense: entre la naturaleza y la cultura de una ciudad moderna e higiénica

En 1882, la ciudad de La Plata se creaba para interrumpir una situación de acefalía en el principal Estado argentino provocada por la federalización de la ciudad de Buenos Aires. Surgía para materializar los acuerdos alcanzados entre la Nación y la Provincia de Buenos Aires tras violentos enfrentamientos ocurridos en 1880, que fueron la consecuencia de una vieja disputa por el control del puerto de Buenos Aires (Vallejo, 2007). Su nacimiento sería parte de un momento glorioso con el que se iniciaba el proceso de organización nacional conducido por la denominada "Generación del '80", que clausuraría viejos enfrentamientos. Así, la Provincia se desprendía de su principal ciudad, a la par que se concentraba en crear una "nueva Capital" en tanto experimento controlado. La Plata será para sus fundadores la metáfora de la ciudad imaginada, del orden propugnado,

el resultado de una superposición de proyectos parciales y también de la inmanente voluntad de situarse en una directa continuidad con la historia «civilizatoria» del país, a su vez deudora del empeño de liberales argentinos en ubicar al evolucionismo darwiniano como clave de legitimación científica del gradualismo político (Vallejo, 2007, p.35).

Será pensada, asimismo, como la ciudad higiénica. Posteriormente, entrará en escena la Universidad, transformándola en la más novedosa ciudad universitaria de Sudamérica. Dardo Rocha, el fundador de La Plata, estimaba que la misma además de ser un centro político, administrativo y económico, debía convertirse en un importante foco cultural.

El Bosque platense va a ser el lugar donde se construirá el campus universitario de La UNLP. Dicho espacio contará con el CN, sus internados y su campo de deportes, como una de sus primeras instituciones, desde los primeros años del siglo XX. De dicho campo de deportes nacerá el DCF, que lo entendemos como la administración de un espacio disponible y la pretensión del establecimiento de cierto 
orden conservador en un movimiento de contrarreforma universitaria en Latinoamérica. El bosque, entonces, va a ser entendido como "la presencia ejemplar del campo en la ciudad, representación del afán moralizador y también de los valores inculcados por la medicina social en las poblaciones urbanas" (Vallejo, 2007, p. 382). Se interpretaba, así, al bosque como la representación del control de los impulsos físicos de la naturaleza que resultó clave dentro de la tradición iluminista.

Destacamos el hecho de que el concepto cultura física se caracterizó por recuperar ciertos ideales corporales griegos, buscar el mejoramiento de la salud y de la especie para contrarrestar la vida sedentaria moderna de las crecientes ciudades, a la vez que establecer cierto deber ser diferenciado, en términos estéticos, para los hombres y las mujeres (Bergel y Palomino, 2000; Botempo, 2012; Dogliotti, 2014). Entonces, construir un DCF en un reducto de lo rural, de lo natural, parece ser una combinación ideal. Así, confluyen (¿y se oponen?), la naturaleza y la cultura. En palabras de Gustavo Vallejo (2007, p. 240), cultura y naturaleza "confluían así en una extraña conjunción de «selva urbana» que transmitía la sensación de «entrar en un baño fresco, oliente a resinas y perfumes de monte» a quien llegaba de la febril actividad de Buenos Aires". Este autor, al referirse a la escuela nueva francesa, referente del proyecto pedagógico de la UNLP, afirma que la interacción entre la naturaleza y la ciudad moderna, que pasaba por una relación de compromiso y distanciamiento con la cultura urbana, devenían en el intento de integrar los beneficios de las dos entidades antitéticas. Esto es, "valerse del mayor grado de libertad e higiene que proporcionaba el campo y al mismo tiempo del progreso material y cultural de la ciudad" (Vallejo, 2007, p. 227). Así, se canalizaba adecuadamente el precepto escolanovista de Ferriére (1922) de situar la escuela en el campo sin alejarse de la ciudad. Además, el elemento verde se aplica sabiamente para suavizar el esquema urbano, mediante la variedad de formas y tamaños de las plazas y parques, contabilizándose en el plano de La Plata, en su forma más desarrollada, doce tipos diferentes, incluyendo al Bosque (Morosi, 1999). Recordemos que la ciudad se trazó a partir de la construcción de 23 parques y plazas, interconectados por bulevares arbolados.

Entendemos que este dualismo naturaleza-cultura está en línea con otras dicotomías que se presentan desde el DCF. Una de ellas tiene que ver con la diferenciación entre mente y cuerpo, ocupándose la dependencia que nos compete del segundo de estos elementos, mientras que otro dualismo, central para este artículo, se vincula con la diferenciación entre cultura física y cultura física femenina. Entendemos que la forma misma de enunciar estos dos conceptos da cuenta de concebir a lo masculino como universal, reservando lo particular para lo femenino. Entonces, siguiendo a Simone de Beauvoir (1949), uno debe entender que los hombres no nacen con una facultad para lo universal y que las mujeres no se circunscriben en el momento de su nacimiento a lo particular. Asimismo, en este sentido, 
operación reguladora de poder que naturaliza el caso hegemónico y reduce la posibilidad de pensar en su alteración (Butler, 2004, pp. 70 y 71).

Lo mismo sucede con los nombres mismos de los colegios, mientras uno es el Nacional -exclusivo para varones, pero sin necesidad de aclarar esta cuestión-, el otro es el Secundario de Señoritas.

Como veremos en el siguiente apartado, los alumnos del CN se desempeñaron en el campo de deportes, mientras que las alumnas del CSS lo hicieron, especialmente, en el gimnasio cerrado y en el patio de la institución. Así, es paradójico cómo los alumnos varones del $\mathrm{CN}$ habitaron un lugar que sería "natural", mientras que las mujeres hacían lo propio en un sitio más ligado a la "cultura", cuando históricamente se ha vinculado a la mujer con la naturaleza, debido a su función materna 6 , y al hombre con la cultura, por haberse desempeñado en gran parte de la historia en el ámbito público y por haber tenido mayor incidencia en la ciencia. Se trata de una manera implícita de justificar, legitimar, la dominación masculina. Es decir, como la cultura es superior y domina a la naturaleza, el hombre es superior y domina a la mujer, siendo esa dominación universal (Ortner, 1972). El mismo Rodríguez Jurado al referir a los deportes y juegos individuales para las mujeres, planteaba que ocuparán una buena parte del tiempo de clase, y que deben estar "adaptados a la naturaleza femenina, que no exijan un mayor esfuerzo y fatiga" (Rodríguez Jurado, 1934, p. 16; el destacado me pertenece). En lo que refiere a esa esencia o naturaleza femenina, Lopes Louro (2004) critica esta idea ya que implica considerar al cuerpo por fuera de la cultura, negando relaciones de poder. En definitiva, la naturaleza siempre fue cultura.

Los espacios escolares diferenciados para la práctica de ejercicios fisicos: abiertos y amplios para ellos, cerrados y más pequeños para ellas

$$
\text { Siguiendo a Scharagrodsky (2019, pp. } 74 \text { y 75), }
$$

los lugares en Educación y en Educación Física siempre han sido abiertos, dinámicos, pero al mismo tiempo, limitados, localizados, circunscriptos, porosos y relacionales. Asimismo, nunca fueron imparciales o ideológicamente desinteresados. Más bien contribuyeron, a partir de ciertas semánticas, a educar en una cierta dirección y no en otra, convirtiéndose en ámbitos de sociabilidad, instalando prácticas y rituales corporales, enseñando ciertas posibilidades e imposibilidades kinéticas, produciendo una especie de adiestramiento sobre la mirada (sobre el qué y cómo mirar el lugar), autorizando y proscribiendo ciertas reglas de presentación y del vestir, potenciando determinadas estéticas, sensibilidades, proxemias, patrones emocionales y formas de enclasar y clasificar al mundo social

La dimensión espacial es vista, de esta manera, como un elemento central y, a la vez, constitutivo de la actividad educativa. Así, a partir de los planteos de este autor, se piensa el lugar como una producción cultural deliberadamente fabricada, con cierta potencia performativa y, a la vez, como una interesante forma de aproximarnos a ciertas lógicas pedagógicopolíticas, ideológicas y culturales que "se han puesto en circulación, 
distribución, transmisión, producción, imposición, pero también que se han negociado, re-significado, apropiado y resistido en un determinado espacio y momento histórico" (Scharagrodsky, 2019, p. 73).

En 1929, Rodríguez Jurado, al referir al espacio físico del campo de deportes, describe la pileta de natación (se indica que estará disponible desde la próxima temporada), las tres canchas de pelota a paleta, las dos canchas de básquet y la de tennis. Asimismo, explica que se están haciendo las gestiones para completar el gimnasio, construir un ring y hacer una pista de atletismo. Aclara, también, que se busca aumentar las comodidades para que resulten un atractivo para los alumnos. Asimismo, se puede leer:

Baños calientes.- Como complemento de todo lo anterior era indispensable la instalación de los baños calientes, a cuyo fin ya funciona una caldera recien instalada que surte de agua a dieciséis lluvias. Esta instalación es de fundamental importancia, permitiendo en invierno la practica de toda clase de ejercicios con las ventajas del baño inmediato al descanso (Rodríguez Jurado, 1929, p. 31).

En cambio, ese año, la asistencia de las alumnas al campo de deportes queda como problema a resolver "ya que no puede hablarse de enseñanzas y práctica especial para las alumnas, sin contarse con instalaciones y vestuarios adecuados" (Rodríguez Jurado, 1929, pp. 31 y 32). Estimamos que esta cita es central, ya que permite entender en su máxima expresión la existencia de relaciones de poder desiguales, al dar por hecho que los vestuarios que están en malas condiciones son los de las mujeres. Es decir, se cuenta con un solo vestuario en condiciones, que no casualmente se asigna de forma natural a los alumnos del CN. Así, para Butler (2018), la «materialidad» designa cierto efecto del poder o, más exactamente, es el poder en sus efectos formativos o constitutivos. En la medida en que el poder opere con éxito constituyendo el terreno de su objeto, un campo de inteligibilidad, sus efectos materiales se consideran datos materiales o hechos primarios. Plantea que estas positividades materiales aparecen fuera del discurso y el poder, como sus referentes indiscutibles, sus significados trascendentales. Pero,

esa aparición es precisamente el momento en el cual más se disimula y resulta más insidiosamente efectivo el régimen del poder/discurso. Cuando este efecto material se juzga como un punto de partida (...), entierra y enmascara efectivamente las relaciones de poder que lo constituyen (Butler, 2018, p. 64).

Zeballos de Heredia $^{7}$ (1930, s/p), directora del CSS, manifestaba que la gimnasia había dependido hasta ese momento del DCF, "pero no siendo posible asistencia del alumnado a las canchas de deportes del Colegio Nacional, creo que debe depender exclusivamente del Liceo, por razones de distancia, disciplina y control". Es importante aclarar que para ese momento el CSS seguía funcionando en el edificio de 1 y 49 , junto al $\mathrm{CN}$ a metros del bosque platense, por lo que el trayecto a recorrer por las alumnas es el mismo que hacían los alumnos: unos 300 metros. Si en cambio, la Directora ya está pensando en el otro edificio a ocupar ${ }^{8}$, la distancia entre este y el campo de deportes del DCF, tomando la diagonal 77, ronda los 800 metros. Entendemos, por este motivo, que se trata de 
una distancia más simbólica que "real" y que, incluso se puede vincular al hecho de que se vea al bosque de la ciudad como un lugar peligroso o inadecuado para las "niñas", en un espacio que contaba en ese momento con pocas edificaciones. Asimismo, somos conscientes que muchas veces las percepciones subjetivas, en este caso de la directora, de las distancias se vinculan entre otras cuestiones al tamaño total de la ciudad. Además, no hemos encontrado fuentes que indiquen que desde la creación del DCF (1929) hasta el traslado de edificio (1931), las alumnas pese a estar menos de 300 metros del campo de deportes hayan asistido al mismo.

Paralelamente, ya para el año 1930, en el campo de deportes se logra que funcione normalmente la pileta de natación y se suma un ring de box (Rodríguez Jurado, 1930). Sin embargo, Rodríguez Jurado (1933, p. 15), con relación a la enseñanza de ejercicios físicos para los varones, produce una "queja" en relación a las instalaciones, pese a contar diferentes lugares para esa práctica, planteando que donde más se hace sentir "esa insuficiencia de elementos es en materia de vestuario, siendo de desear se prosigan las obras de un nuevo cuerpo de los mismos, que ha dejado sin terminar la Dirección general de arquitectura de la Nación” (p. 15). Para el año 1934, Rodríguez Jurado insiste en la falta de comodidades en el vestuario para los varones. Ese mismo año se hace referencia a que el plan de acción a seguir para la enseñanza de las alumnas no pudo aplicarse debido al traslado del colegio a otro edificio, "donde no se cuenta con las comodidades e instalaciones indispensables para su aplicación” (Rodríguez Jurado, 1934, p. 12). Luego se plantea que las clases de gimnasia se dicten en horas de la tarde en el establecimiento del CSS y que una vez por semana concurran al campo de deportes. En ese sentido, Rodríguez Jurado refiriéndose al presidente de la UNLP, aclara que "en varias oportunidades, de acuerdo con la señora Directora, las alumnas han concurrido a este Departamento, acompañadas de las señoritas profesoras, a hacer práctica de atletismo y pelota al cesto" (Rodríguez Jurado, 1934, p.13). Esto da a entender que lo habitual era que las alumnas hicieran las clases de educación física en el gimnasio del CSS, creado ese mismo año, y en el patio de dicha institución.

En el discurso de asunción como directora, en el año 1934, Juana Cortelezzi ${ }^{9}$ plantea su postura al respecto de los espacios para la práctica de la Educación Física:

Nadie disiente hoy en cuento a los beneficios que proporciona la educación física, no solo desde el punto de vista corporal sinó también espiritual. Es cierto que nuestra ciudad posee ya buenas instituciones deportivas, pero durante el período escolar es difícil frecuentarlas con regularidad. Es necesario pues preocuparse seriamente del cultivo sistemático de esta actividad dentro del colegio. El nuevo edificio, que podrá ser dotado de las instalaciones necesarias, nos permitirá realizarla siguiendo los principios científicos más modernos (Cortelezzi, 1934, p. 128).

Pese a este presunto desinterés por parte del CSS de que las alumnas asistan al campo de deportes, desde la prensa gráfica (El Argentino, 11 de diciembre de 1934; El Día, 11 de diciembre de 1934) se difunde la invitación a las educandas a clases de natación en la pileta de dicho 
espacio, durante el verano. Los alumnos, en cambio, realizaban todas sus clases en el campo de deportes. Así, Rodríguez Jurado (1935), plantea que Joaquín V. González, fundador de la UNLP, con una visión clara sobre las ventajas de la práctica y enseñanza de la cultura física para los alumnos del CN, al proyectar el edificio que actualmente ocupa el Colegio, dispuso se destinara una gran extensión de tierra para instalar un campo de deportes, siendo así como se construyeron allí diferentes instalaciones. Recién ese año plantea que se ha resuelto el problema de los vestuarios de las mujeres en el campo de deportes, "llenándose con ello una necesidad bien sentida, pues las numerosas alumnas que concurren a hacer uso de las instalaciones del Departamento no tenían comodidades suficientes" (Rodríguez Jurado, 1935, p. 202). Sin embargo, nos encontramos con que ese año la exhibición de gimnasia de fin de año se realiza en el CSS, añadiendo más elementos a la suposición de que se trata de espacios claramente diferenciados.

En la memoria del CSS del año 1935, la directora afirmará que "en estos momentos se inician los trabajos tendientes a dotar al colegio de canchas de juegos canchas de deportes, lo que es factible dado el amplio terreno que rodea al edificio por las calles 47 y 6" (Cortelezzi, 1935, p. 5). Esta situación de práctica en espacios diferenciados, parece extenderse a los años siguientes, incluso hasta el final del período analizado. Así, una exalumna de 1er año del CSS en 1936 (entrevistada en mayo de $2017^{10}$ ) afirma que las clases de gimnasia se realizaban en el mismo establecimiento (gimnasio y patio cerrado) y no en el campo de deportes.

Entonces, se confina a la mujer al espacio privado a través de la práctica de ejercicios físicos, en el caso analizado, lo que se ve reforzado por el dictado de cursos obligatorios como "ciencias domésticas" y "puericultura" (aunque solo se enseñan con el plan de estudios de 1926, que rige hasta 1930, lo que significa que abarca solo el primer año analizado), contando también, desde 1938, con clases optativas de cocina. Hay una gran diferencia entre esas dos disciplinas -ciencias domésticas y puericultura-: mientras que las expertas en ciencias domésticas fueron en su mayoría mujeres, no ocurrió lo mismo con la crianza científica de los niños (la puericultura). La educación estatal nació al calor de una función política específica: socializar las nuevas generaciones dentro del marco de referencia de la cultura dominante (Nari, 1995). Se pretendía reproducir el orden social, por lo que se imponía educar al soberano. Esa autora plantea que evidentemente, el ciudadano era un varón, puesto que no se esperaba de las niñas una participación directa en la política; aunque sí, de manera vicaria. "Y si educar al varón era, ante todo, formar al ciudadano; educar a la mujer era construir a la madre/esposa del ciudadano" (Nari, 1995, p. 35). La reproducción de la división sexual del trabajo (y de las relaciones asimétricas de poder entre hombres y mujeres) fue asegurada desde el mismo currículum. Esto se enmarca en una concepción de la población como riqueza, ya que detrás de las preocupaciones acerca de la mortalidad infantil, la minoridad abandonada, los abortos y los infanticidios, se hallaba un nuevo concepto utilitario del niño como capital que hay que conservar y aumentar para asegurar la salud y fuerza 
de las naciones (Nari, 1995). Así, el nacimiento de la puericultura debe entenderse dentro de un proceso más amplio que condujo a la medicalización del embarazo, del parto y del cuidado de los niños.

Además, desde el DCF, se establecía una vinculación entre la función materna (propia del espacio privado) y los ejercicios físicos prescriptos para las alumnas, a partir de los planteos de Mauricie Boigey (Rodríguez Jurado, 1934), un médico francés eugenista, que planteaba la ejercitación de ciertas partes del cuerpo pensando en la función materna en la búsqueda del mejoramiento de la raza.

La práctica en un espacio cerrado para el caso de las alumnas remite a la idea de vincular a las mujeres naturalmente al espacio privado, mientras que el espacio público se reserva para los hombres. Entonces, si pensamos en el espacio y los procesos de jerarquización sexual anclados en esencialismos biológicos, como alude Fausto-Sterling (2006), para el contexto estadounidense de principios del siglo XX, la idea de que la esfera pública era masculina por definición estaba tan profundamente implantada en el tejido metafísico de ese período que parecía natural argumentar que las mujeres que aspiraban a los Derechos del Hombre tenían que ser también masculinas por definición. Así, siguiendo a Delgado de Smith (2008), lo femenino, asignado a la mujer, se ubica de modo exclusivo en el ámbito privado, doméstico, familiar. El ámbito privado aparece como el propio de la mujer, la cual por naturaleza podría desempeñarse mejor en ese sentido: "es el espacio del cuidado, de la atención a los otros, de los afectos, de la reproducción de la vida, del trabajo no remunerado e invisible" (Delgado de Smith, 2008, p. 117). De este modo, como afirma Cantón Mayo (2007, p. 119), en el espacio se pueden distinguir dos planos igualmente importantes: uno referencial y otro simbólico. Así, "la función referencial toma el espacio como lugar concreto y perceptible, mientras que la función simbólica lo asocia al poder y al estatus de quien lo ocupa". O sea, lo que simbolizan los espacios concretos que se utilizan para la práctica diferenciada de ejercicios físicos son los lugares adecuados, o incluso naturales, para unas y para otros.

De este modo, los muros del edificio del CSS, en términos pedagógicos, se tradujeron en muros simbólicos (Serra, 2019), que limitaron, para las alumnas, el acceso a ciertos espacios abiertos de la ciudad, contribuyendo a la transmisión de cierta manera de ser mujer, ligada al ámbito cerrado y doméstico. En este sentido, es posible pensar a los muros no solo en términos coercitivos o restrictivos, sino también productivos (Malpas, 2015): produjeron cuerpos sexuados y desiguales relaciones de poder, que derivaron en desiguales fines macropolíticos

No obstante, otras iniciativas van el sentido contrario: el de fomentar en las alumnas la ocupación de espacios públicos. Esto último se ve, por ejemplo, en la realización de excursiones en 1932 a Sierra de la Ventana (El Argentino, 15 de diciembre de 1932) o de un campamento en la ciudad balnearia de Mar del Plata (Provincia de Buenos Aires) en enero de 1936, catalogado como el primer campamento femenino llevado a cabo en este sitio turístico (Ortube, 2001). Los varones del CN y de la 
escuela graduada al menos desde 1932 también realizaban campamentos y colonias de vacaciones, respectivamente (Rodríguez Jurado, 1934).

Avanzando cronológicamente, Rodríguez Jurado (1937), en un artículo dedicado al DCF, afirma que "un campo de deportes es la alegría y la salud prodigándose a manos llenas, por influencia del sol, del aire, del agua y de los ejercicios gimnásticos" (p.288); así “ese campo de deportes es, además de un espacio libre, un sitio donde la naturaleza, en la exuberancia de los árboles y en la belleza de las flores pone su nota de belleza, puede decirse que es perfecto" (p. 288). De este modo, esa referencia al espacio combina elementos propios del higienismo con referencias a la naturaleza y a lo estético, en línea con lo ya planteado. La siguiente referencia de ese mismo texto, que plantea un claro dualismo mente-cuerpo, podría indicar que no se llevaba a cabo efectivamente la división de espacios para la práctica de ejercicios físicos: "en las horas de la mañana y de la tarde, las instalaciones se llenan de jóvenes de ambos sexos que dejaron el aula, donde cultivan su espíritu, para cultivar el cuerpo en ese campo de deportes” (p.289, el destacado nos pertenece). Más allá de esas palabras, las fotos que se incluyen en dicho artículo presentan a alumnas realizando ejercicios físicos no en el campo de deportes, sino en el patio del CSS.

Así, la diferenciación entre lo público y lo privado es un proceso general que opera como un eje ordenador en la experiencia de los sujetos sociales (Tófoli, 2016). Sin embargo, como en toda relación social, en esta problemática de la ocupación de los espacios para la práctica de ejercicios físicos, que se traduce en relaciones desiguales de poder, no hay un determinismo absoluto ni por parte del discurso, ni por parte del propio espacio físico, sino que se producen disputas, resignificaciones, resistencias, diferentes maneras de habitar y transformar el espacio. Así,

Ni el ser humano determina unívocamente el entorno en el que se desarrolla ni el espacio hace lo propio en relación con el comportamiento de las personas. Es la propia relación persona-entorno la que da sentido a nuestra vida permanentemente contextualizada en el espacio y la que, a su vez, define ambas instancias: con nuestros actos transformamos y dotamos de significado, de sentido al entorno mientras que éste contribuye de manera decisiva a definir quiénes somos, a ubicarnos no solo ambiental sino personal y socialmente y a establecer modalidades de relación con nuestro mundo perceptivo, funcional y simbólico (Valera, 1999, p. 23).

Llegados a este punto es necesario aclarar que ni abierto es sinónimo de público, ni cerrado lo de es privado. Existen lugares cerrados públicos, del mismo modo que hay lugares abiertos y privados. A partir del recorrido histórico que emprende, De Barbieri (1996, p. 10) afirma que

el núcleo duro de la distinción entre lo público y lo privado parece encontrarse en la teoría del contrato social. Subyace a la elaboración conceptual que cuestiona el ordenamiento feudal y posibilita la constitución de la democracia burguesa, la aparición del individuo libre -ciudadano en quien descansa la soberanía de la nación y del Estado moderno- (...). Así se construye la sociedad civil, como la suma de los individuos-ciudadanos. Público y privado son las esferas en que se divide la sociedad civil. En la primera, que fue objeto de reflexión de los contractualistas, acontecen las actividades propias de la ciudadanía. La privada, en cambio, no es política por definición 
En el año 1938, se hace referencia una vez más a los inconvenientes edilicios del campo de deportes:

El Departamento de cultura física intenta ponerse a tono con los principios y conceptos modernos de la educación física. Pero la estrechez de medios, la insuficiencia material de las instalaciones y elementos y lo reducido de su órbita didáctica, obstaculizan de una manera indudable, el hondo anhelo de los que tenemos la responsabilidad de su orientación y la no menos responsabilidad de su eficacia (Rodríguez Jurado, 1938, p. 190).

Ese mismo año, en relación a los espacios donde se desempeñan las alumnas, y al hacer referencia al nuevo plan, se dice que

\begin{abstract}
Desde luego para que su aplicación pueda ser efectiva se requiere que el Colegio cuente con la suficiente comodidad de baños y vestuarios, los cuales han sido solicitados por nota para que la Dirección de arquitectura ordene con urgencia su construcción.

Con respecto a las comodidades con que cuenta actualmente el Colegio secundario de señoritas, debo informarle que merced al efusivo interés puesto por la directora en lo que a educación física se refiere, fué posible la instalación de un gimnasio en condiciones excelentes para la práctica de calistenia, construyéndose también en el patio una cancha de basket-ball y otra de bolley-ball. Esta Dirección ha suministrado al Colegio el material deportivo necesario, dentro de lo que este Departamento pudo suministrar, sin resentir la normalidad de sus servicios (Rodríguez Jurado, 1938, p.195).
\end{abstract}

Entonces, a partir de esta clase de referencias, confirmamos una vez más que las alumnas llevaban a cabo sus clases de ejercicios físicos en el colegio, no asistiendo regularmente al campo de deportes, afianzando esta diferenciación espacial y que, pese a la diferencia del año 1929 en torno a los vestuarios, las condiciones edilicias para los alumnos del CN no son mucho mejores que las de las mujeres.

Sin embargo, en el mismo texto se dice que "se han facilitado asimismo los campos y canchas para que fueran utilizadas por las alumnas, poniendo a disposición de las mismas la pileta de natación, fijando en el horario, un día exclusivo para ellas" (Rodríguez Jurado, 1938, p. 196). Esto, obviamente, nos lleva a relativizar nuestras afirmaciones anteriores, aunque adiciona un elemento más: las alumnas asisten a la pileta del campo de deportes, pero cuentan con un día especial para ellas, donde no se permite la entrada de hombres, lo que contribuye una vez más al binarismo sexual, la educación diferenciada, y la separación espacial. La enseñanza diferenciada y la separación espacial entre el CSS y el CN estaba en línea con lo ocurrido en instancias de formación de profesores/as de Educación Física (Scharagrodsky, 2006b).

No obstante, si tenemos en cuenta la palabra de dos exalumnas del CSS entre 1941 y 1946, y entre los años 1943 y 1948, respectivamente, no quedan dudas: mientras la primera plantea que no conoció el campo de deportes, ya que solo tenía clases en el gimnasio cerrado de la escuela (no teniendo clases ni siquiera en el patio de dicha institución), la segunda expresa que asistió al campo de deportes recién el año 1947 (entrevista realizada en marzo de 2019) ${ }^{11}$. 
En abril de 1944, en un libro de actas de reuniones del CSS, se plantea que debieron suspenderse algunas clases de gimnasia de los años superiores por dictarse durante la tarde antes de la clase de música por no disponerse de baños, repitiendo que se ha solicitado reiteradamente su construcción a la Dirección de Arquitectura por anteriores Direcciones (del CSS). Eso nos permite leer dos cuestiones fundamentales que hacen al uso del espacio diferenciado, desde una perspectiva de género. La primera, se vincula al hecho de confirmar que todavía, ya entrando en los últimos años del período analizado, las alumnas siguen teniendo clases en el edificio del CSS y no en el campo de deportes. La segunda, se trata del hecho de que existe una desigualdad en relación a los varones, ya que ellos en el campo de deportes que utilizan, ya cuentan con duchas desde al menos el año 1929.

Asimismo, en relación al campo de deportes, hemos tenido conocimiento de un anteproyecto para la realización de una importante ampliación del mismo del año $1942^{12}$. Se trataba de la construcción de un gimnasio cubierto compuesto por dos plantas y una importante tribuna. El mismo, incluía halls, oficinas, depósitos, vestuarios, palcos, donde se preveía instalar dos canchas de básquet (consulta a Centro de documentación e investigación de la Arquitectura Pública). El proyecto finalmente no se llevó a cabo, pero da cuenta de la importancia asignada a este espacio, de uso predominantemente masculino, y de la magnitud de las obras que se idearon para ampliarlo.

En relación a la discusión que venimos desarrollando, en el libro del Liceo Víctor Mercante (ex CSS), publicado en el año 2001, se plantea que:

En 1947 las clases se trasladan al Campo de Deportes y los profesores dejan de figurar en el presupuesto del Liceo.

En muchas de las memorias posteriores a ese año se ha dejado constancia de los inconvenientes suscitados por esa medida: la falta de medios de transporte para llegar hasta el Campo; la desconección [sic] con el colegio; lo aislado del lugar que hizo que muchas veces se vieran los directivos en la necesidad de solicitar vigilancia policial; por deficiencias higiénicas, etc. (Ortube, 2001, p. 378).

Ello, pese a que entendemos que dicha publicación no es resultado, estrictamente, de una investigación rigurosa, nos confirma que las clases se daban predominantemente en el Colegio, y que el rechazo, por inconvenientes reales o ficticios, a asistir al campo, continuó en períodos posteriores.

\section{Consideraciones finales}

Adherimos a la idea de que los espacios, con sus dimensiones, formas, características generales, no son neutrales. Por el contrario, transmiten sentidos, significados, pudiendo ser entendidos como metáforas sociales, que se vinculan, entre otras cuestiones, al género y a las relaciones de poder, correspondiendo a cuestiones políticas. En lo que hace al ámbito educativo, este proceso implica que los espacios educan, transmiten un currículum implícito u oculto que sexualiza y generiza, estableciendo posibles e imposibles para cada género, fomentando universos morales, estéticos, kinéticos y fines macropolíticos desiguales. 
En nuestro caso concreto, nos encontramos con que los alumnos y las alumnas para su educación general (más allá de la cultura física), en el período abordado, contaron con edificios claramente disímiles (no abordados en este artículo). Mientras los primeros se desempeñaron en un lugar de importantes dimensiones, construido especialmente para ellos, que tiene características similares a la "gran arquitectura" de la administración pública de la ciudad, con capacidad para más de mil alumnos; las alumnas contaron con un edificio que al momento de la mudanza ya contaba con 43 años de antigüedad y malas condiciones materiales, dimensiones claramente inferiores (a partir de una política de aprovechamiento de medias manzanas producidas por el paso de las diagonales), que, a lo largo del período analizado debió ser compartido, en ocasiones, con otra escuela media para mujeres, un jardín de infantes y una escuela primaria para niñas.

En lo que respecta a los lugares parta la práctica de ejercicios físicos, hallamos un vaivén permanente entre compartir alumnos y alumnas el espacio del campo de deportes, por un lado, y que ese lugar fuera exclusivo para los hombres y que las mujeres se desempeñaran en el gimnasio cerrado y en el patio del Colegio, por el otro, predominando la segunda opción. De esta manera, el campo de deportes era un espacio público, abierto, en el que circulaban no solo estudiantes del CN, sino estudiantes universitarios, y donde era habitual que asistieran también estudiantes de otras universidades y otros colegios de enseñanza media a disputar torneos en la piscina de dimensiones olímpicas, en la pista de atletismo, en el ring de box, o en las canchas de tenis, pelota a paleta, básquet, fútbol, y pelota al cesto, entre otras. El espacio del CSS, en cambio, era cerrado y mucho más pequeño, y por él circulaban, solamente, alumnas del colegio y personal docente y administrativo predominantemente femenino. Allí, se contaba con una cancha de básquet y de vóley, practicando también pelota al cesto, en lo que respecta al patio, y se llevaban a cabo clases de gimnasia rítmica o expresiva, al ritmo del piano ubicado en el gimnasio cerrado.

Entonces, pese a esgrimirse desde el CSS que no era conveniente que las alumnas asistieron al campo de deportes por razones de seguridad, distancia, disciplina, control, higiene, y condiciones edilicias adecuadas, entendemos que lo que en realidad ocurría era que se estimaba que el espacio cerrado, poco transitado, pequeño, tras los muros de la escuela, era el pensado como el más adecuado para ellas, futuras madres a desempeñarse en el ámbito privado y vistas como seres más débiles y pasivas que los hombres. Insistimos en el hecho de que no se trató de una ausencia absoluta de las mujeres en el campo de deportes, pero ante el hallazgo de fuentes que dan cuenta de que las alumnas asistían al mismo, inmediatamente se cuenta con muchas otras que contradicen esta cuestión. Por el lado de los hombres, se los ligó a la actividad, la autonomía y la responsabilidad.

Es necesario aclarar que el espacio fue una de las dimensiones que contribuyeron en la generización y sexualización de los cuerpos desde el currículum de la Educación Física, ya que este proceso se llevó a cabo también a partir de la producción de prácticas y discursos diferenciados, 
que generaron la ejercitación de capacidades motoras disímiles y el desarrollo de distintas partes del cuerpo, a partir de la utilización de diferentes materiales para unas y otros. Lo realizado desde la Educación Física estaba en sintonía con contenidos de otras asignaturas que pensaron en el desempeño en el ámbito privado para las mujeres, como fueron Ciencias Domésticas, Puericultura (ambas obligatorias) y Cocina y Costura (optativas). Así, se contribuyó desde el currículum a afianzar la existencia de ciudadanos de primera y de ciudadanas de segunda (Giordano, 2014), lo que se evidenciaba, entre otras cosas, en el hecho de que las mujeres no pudieron votar, ni ser electas como representantes del pueblo, hasta el año 1947. No obstante, las alumnas contaron también con materias como "Política y Economía" e "Instrucción Cívica", que las acercarían a un desempeño en el ámbito público, a la vez que realizaron campamentos en sitios turísticos. Por ello, tanto en lo que a contenidos se refiere, como a lo que acontece con el vivir los espacios, siempre hay lugar para las resignificaciones, las luchas, las disputas, las resistencias. En definitiva, la realidad social es compleja, ambigua, contradictoria.

\section{Referencias bibliográficas}

Aisenstein, A. (2006). El discurso pedagógico en Educación Física. La tensión ciencia vs. Espíritu en la conformación de una disciplina escolar. En A. Aisenstein, A. y P. Scharagrodsky (Coord.). Tras las huellas de la Educación Física Escolar Argentina. Cuerpo, género y pedagogía 1880-1950 (pp. 49-71). Buenos Aires: Prometeo.

Aisenstein, A. (2008). Tensiones en el discurso de la Educación Física: definiciones en la prensa pedagógica, Argentina 1900-1940. En Scharagrodsky, P. (compilador). Gobernar es ejercitar. Fragmentos históricos de la Educación Física en Iberoamérica. Buenos Aires: Prometeo. 65- 74.

Aisenstein, A. y Scharagrodsky, P (2006). Tras las huellas de la Educación Física Escolar Argentina. Cuerpo, género y pedagogía 1880-1950. Buenos Aires: Prometeo.

Badinter, E. (1993). XY, la identidad masculina. Santa Fe de Bogotá: Grupo Editorial Norma.

Barbosa Cruz, R. (2008). El trabajo en las calles. Subsistencia y negociación politica en la ciudad de México a comienzos del siglo XIX. Mexico DF: Colmex.

Beauvoir, S. (1949). Le deuxieme sexe. París: Gallimard.

Bejar, M. (2005). El régimen fraudulento en la provincia de Buenos Aires, 1930-1943. Buenos Aires: Siglo XXI.

Belinche, M. y Panella, C. (2014). Memorias de la universidad: Un relato fotográfico sobre la identidad de la UNLP. La Plata: Edulp.

Bergel, M. y Palomino, P. (2000). La Revista El Gráfico en sus inicios: una pedagogía deportiva para la ciudad moderna. Prismas: Revista de Historia intelectual, n4, pp. 103-124. https://dialnet.unirioja.es/ejemplar/362981

Botempo, M. (2012). Editorial Atlántida: un continente de publicaciones, 1918-1936 (tesis doctoral). Universidad de San Andrés, Victoria. 
Britto, F. y Jacques, P. (2012). Corpo \& Cidade: coimplicações em processo. Revista UFMG, v.19, n.1 e 2, pp. 142-155. https://periodicos.ufmg.br/in dex.php/revistadaufmg/article/view/2716

Burin, M. y Meler, I. (2009). Varones. Género y subjetividad masculina. Buenos Aires: Librería de Mujeres Editoras.

Butler, J. (2004). Deshacer el género. Paidós: Buenos Aires.

Butler, J. (2006). Regulaciones de género. La ventana, n.23, pp. 7-35. http://www.scielo.org.mx/scielo.php?script=sci_arttext\&pid=S14 05-94362006000100007\&lng=es\&nrm=iso

Butler, J. (2018). Cuerpo que importan. Sobre los límites materiales y discursivos del "sexo". Paidós: Buenos Aires.

Cantón Mayo, I. (2007). El espacio educativo y las referencias al género. Revista Interuniversitaria de Formación del Profesorado, 21(2/3), pp. 115-135. ht tps://dialnet.unirioja.es/servlet/articulo?codigo $=2541003$

Casey, E. (1996). The Fate of Place: A Philosophical History. Berkeley: CA. California University Press.

Cattaruza, A. (2009). La Historia de la Argentina. 1916-1955. Buenos Aires: Siglo XXI.

Centro de Documentación e Investigación de la Arquitectura Pública. Ministerio de Hacienda de la República Argentina. https://portalcdi.mecon.gob.ar/cgi-bin/wxis.exe/iah/scripts/ ?IsisScript $=$ iah. $x$ is\&lang $=$ es\&base $=$ CEDIAP

Chaoul Pereyra, M. (2019). Ciudad, espacios y la cultura material de la escuela primaria en México hacia finales del siglo XIX y principios del XX. Anuario de Historia de la Educación, ${ }^{\circ} 1$, pp. 11-27. http://ppct.caicyt.go v.ar/index.php/anuario/article/view/15531

Colegio Secundario de Señoritas. Plan de estudios de 1926. Universidad Nacional de La Plata.

Connell, R. W. (2001). Educando a los muchachos: nuevas investigaciones sobre masculinidad y estrategias de género para las escuelas. Nómadas, núm. 14, pp. 156-171. http://www.bdigital.unal.edu.co/48100/1/educandoalosm uchachos.PDF

Cortelezzi, J. (1934). Palabras pronunciadas al asumir la Dirección del Colegio Secundario de Señoritas. Universidad Nacional de La Plata.

De Barbieri, T. (1996). Los ámbitos de acción de las mujeres, en: Narda Henríquez (ed.). Encrujiadas del saber: los estudios de género en las ciencias sociales. pp. 107-132.

De Lauretis, T. (2000). Tecnología de género. En Diferencias: etapas de un camino a través del feminismo. Madrid: Horas y Horas.

Del Valle, T. (1995). El Espacio y el tiempo en las relaciones de género. La Ventana, n.3, p.97-133. https://www.bizkaia.eus/fitxategiak/04/ondarea/Kobie/PDF /5/Kobie_5_Antrpologia_cultural_EL\%20ESPACIO\%20Y\%20EL\%20 TIEMPO\%20EN\%20LAS\%20RELACIONES\%20DE\%20GENERO.p df?hash $=1 \mathrm{~b} 0490744 \mathrm{f2a} 26 \mathrm{ef} 8 \mathrm{aa} 05 \mathrm{e} 9805 \mathrm{f} 43218$

Delgado de Smith, Y. (2008). El sujeto: los espacios públicos y privados desde el género. Revista Estudios Culturales. n², pp. 113-126. 
Di Piero, M. (2018). Procesos de jerarquización en secundarias universitarias en Argentina. Universitas, 28, pp. 61-78. https://universitas.ups.edu.ec/inde x.php/universitas/article/view/28.2018.03

Diario El Argentino (11 de diciembre de 1934). Colegio Secundario de Señoritas. Curso de la natación en el departamento de cultura física. P. 23.

Diario El Argentino (15 de diciembre de 1932). Colegio Secundario de Señoritas. Excursión a Sierra de la Ventana. P. 17.

Diario El Día (11 de diciembre de 1934). Universitarias. Colegio Secundario de Señoritas. Cursos de natación en el Departamento de Cultura Física. P. 26.

Díaz Villa, G. y Ortmann, C. (2011) El género (femenino) en disputa. Acerca de la problematización de las mujers como contenido escolar. En: Actas IV Coloquio Educación, sexualidades y relaciones de género. Noviembre.

Dogliotti, P. (2014). Acerca de la "Cultura Física" en la revista Uruguay-Sport: Archivos de la CNEF, Uruguay (1918-1926). Revista brasileira de Ciencias do Esporte. Vol 36, n 3, pp. 608-616. https://www.sciencedirect.com/scie nce/article/pii/S0101328914700022

Dussel, I. (1997). Curriculum, humanismo y democracia en la enseñanza media (1863-1920). Buenos Aires: FLACSO.

Escolano Benito, A. (2000). Tiemposy espacios para la escuela. Madrid: Biblioteca Nueva.

Fausto Sterling, A. (2006). Cuerpos sexuados. La política de género y la construcción de la sexualidad. Barcelona: Melusina.

Ferriére Adolphe (1922). L'ecole active. París: Forum.

Fuller, N. (1997). Identidades masculinas. Hombres de clase media en el Perú. Perú: Pontificia Universidad Católica del Perú.

Galak, E. (2012). Del dicho al hecho (y viceversa). El largo trecho de la construcción del campo de la formación profesional de la Educación Física en Argentina. Legalidades, legitimidades, discursos y prácticas en la institucionalización de su oficio entre finales del siglo XIX y el primer tercio del XX (tesis doctoral). Universidad Nacional de La Plata, La Plata.

García, S. (2011). Mujeres, Ciencias Naturales y empleo académico en la Argentina. Interthesis, vol 8, n2, pp. 83-103. https://ri.conicet.gov.ar/han dle/11336/80548

Gentile, E. y Vallejo, G. (1999). De los Internados al Hogar estudiantil El hábitat en los proyectos pedagógicos de la UNLP (1905/10-1924). En H. Biagini compilador, La Universidad de La Plata y el movimiento estudiantil, desde sus origenes hasta 1930, La Plata: EDULP, pp. 87-111.

Gilmore, D. D. (1990). Manhood in the making: Cultural concepts of masculinity. Yale University Press.

Giordano, V. (2014). (Doble) moral sexual y derechos civiles de las mujeres, 1888-2010. En Barrancos, D.; Guy, D.; Valobra, A. (editoras). Moralidades y comportamientos sexuales. Argentina, 1880-2011. Ciudad Autónoma de Buenos Aires: Biblos.

Kopelovich, P. (2019). Biopoder y Departamento de Cultura Física (Universidad Nacional de La Plata, 1929-1946). Agora para la Educación Física y el deporte, 21, pp. 170-192. https://revistas.uva.es/index.php/ago $\mathrm{ra} /$ article/view/4089

Kopelovich, P. (2020). Departamento de Cultura Física (1929-1946) y Dirección General de Educación Física (1947) de la Universidad Nacional 
de La Plata. Continuidades y rupturas en sus discursos legitimantes. Rev. Tempos Espaços Educ. v.13, n. 32, e-13608, jan./dez.2020, pp. 1-19. https: //seer.ufs.br/index.php/revtee/article/view/13608

Lamas, M. (2000). Diferencias de sexo, género y diferencia sexual. Cuicuilco, vol. 7, núm. 18, pp. 1-24. https://hum.unne.edu.ar/generoysex/seminario1/s 1_08.pdf

Lefebvre, H. (2013). La producción del espacio. Madrid: Capitán Swing.

Legarralde, M. (1999). Historia del Colegio Nacional de La Plata entre 1887 y 1918, y su articulación con los proyectos pedagógicos. Informe anual. Inédito.

Leindenberg, G. (2004). Proximidad y diferenciación: el manejo del concepto de espacio en la historiografía urbana. Historia y Grafia, n22, pp. 51-79.

Lomas, C. (2014). La coeducación de la masculinidad y el aprendizaje de la equidad. En Piedra de la Cuadra, J. (coord.). Género, masculinidades y diversidad: Educación Física, deporte e identidades masculinas. Barcelona: Octaedro.

Lopes Louro, G. (2004). Marcas del cuerpo, marcas del poder. En Un cuerpo extraño. Ensayos sobre sexualidad y teoría queer. Sao Pablo: Ed. Auténtica.

Malpas, J (2015) Pensar topográficamente: Lugar, espacio y geografía. Documents d'Análisi Geogràfica, vol. 61, no 2, pp. 199-229. https://dag.re vista.uab.es/article/view/v61-n2-malpas/0

Martínez-Herrera, M. (2007). La construcción de la feminidad: la mujer como sujeto de la historia y como sujeto de deseo. Actual. psicol. v.21, n.108, pp.79-95. http://pepsic.bvsalud.org/scielo.php?script=sci_arttext\&pid= S0258-64442007000100004

Massey, D. (2005). For Space. Londres: Sage.

Molina Jiménez, I. (1996). De la historia local a la historia social: algunas notas metodológicas. Reflexiones, Vol. 51, n 1, pp. 20-27. https://dialnet.unirio ja.es/servlet/articulo?codigo $=4796561$

Morgade, G. (2011) (coord..). Toda educación es sexual. Buenos Aires: La Crujía.

Morosi, J. (1999). Ciudad de La Plata. Tres décadas de reflexiones acerca de un singular espacio urbano. Ministerio de la Producción y el Empleo de la Provincia de Buenos Aires.

Nari, M. (1995). La educación de la mujer (o acerca de cómo cocinar y cambiar los pañales a su bebé de manera científica). Revista Mora, nº 1, pp. 31-45.

Olavarría, J. (2004). Modelos de masculinidad y desigualdad de género. En Lomas, C. (comp.), Los chicos también lloran. Identidades masculinas, igualdad entre los sexos y coeducación. Barcelona: Paidós.

Ortega Ibarra, C. y Dussel, I. (2019). Espacio y escuela en perspectiva histórica: aportes latinoamericanos. Anuario Historia de la Educación. Vol 9, n ${ }^{\circ}$, pp. 6-10. http://ppct.caicyt.gov.ar/index.php/anuario/article/view/16638

Ortner, S. (1972). Is Female to Male as Nature is to Culture?. Feminist Studies, I(2), pp. 5-31. Revisado y reimpreso en Michelle Rosaldo y Louise Lamphere, Eds. Woman, Culture and Society. Stanford: Standford University Press.

Ortube, M. (2001). Nuestro Liceo. La Plata: Universidad Nacional de La Plata.

Picato, P. (2001). City of suspects. Crime in Mexico City, 1900-1931. Londres: Duke University Press. 
Pineau, P. (1999). Renovación, represión, cooptación. Las estrategias de la Reforma Fresco-Noble (Provincia de Buenos Aires, Década del 30). En Ascolani, A. (Comp.). La educación en Argentina. Estudios de historia . Rosario: Ediciones del Arca, pp. 223-239.

Pinkasz, D. y Pitelli, C. Las reformas educativas en la provincia de Buenos Aires (1934 -1972): ¿cambiar o conservar? En Puiggrós, A. La educación en las provincias y territorios nacionales (1945 - 1985). Buenos Aires: Galerna

Reitano, E. (2005). Manuel Fresco. Entre la renovación y el fraude. Buenos Aires: Instituto Cultural de la Provincia de Buenos Aires-Archivo Histórico.

Rodríguez Jurado, B. (1929). Departamento de Cultura Física. En boletín anual del Colegio de la Universidad de La Plata. Número 1.

Rodríguez Jurado, B. (1930). La Cultura Física en el Colegio. En boletín anual del Colegio de la Universidad de La Plata. Número 2.

Rodríguez Jurado, B. (1933). Boletín de la Universidad Nacional de La Plata. Tomo XVII. Núm. 1.

Rodríguez Jurado, B. (1934). Informe del año 1933 sobre el desempeño del Departamento de Cultura Física de la UNLP. Archivo histórico del Liceo Víctor Mercante.

Rodríguez Jurado, B. (1935). El departamento de cultura física del Colegio Nacional. Boletín de la Universidad Nacional de La Plata. Tomo XIX. Número 1.

Rodríguez Jurado, B. (1936). En el país de los rascacielos y el deporte. El Gráfico, 8 de febrero de 1936.

Rodríguez Jurado, B. (1937). La cultura física en la universidad nacional de la plata. Revista cultura sexual y física.

Rodríguez Jurado, B. (1938). Informe del departamento de cultura física. Memorias e informes de las autoridades y de los profesores. Universidad Nacional de La Plata.

Romero, J. (1995). Breve historia contemporánea de la Argentina. Buenos Aires: Fondo de cultura

Sautu, R; Boniolo, P.; Dalle, P.; Elbert, R. (2005). Manual de metodología: construcción del marco teórico, formulación de los objetivos y elección de la metodología. Buenos Aires: CLACSO.

Scharagrodsky, P. (2001). De la testosterona a la virilidad: Visibilizando una política escolar generizada. Educación Física y Ciencia, 5, pp. 78-90. http:/ /www.memoria.fahce.unlp.edu.ar/library?a $=\mathrm{d} \& \mathrm{c}=\operatorname{arti} \& \mathrm{~d}=\mathrm{Jpr} 96$

Scharagrodsky, P. (2006a). Construyendo masculinidades y feminidades católicas y moralmente correctas. El caso de la primera Dirección General de Educación Física Argentina (1936-1940). En A. Aisenstein, A. y P. Scharagrodsky (Coord.). Tras las huellas de la Educación Física Escolar Argentina. Cuerpo, género y pedagogía 1880-1950 (pp. 199-234). Buenos Aires: Prometeo.

Scharagrdosky, P. (2006b). El padre de la Educación Física argentina: fabricando una política corporal generizada. En A. Aisenstein, A. y P. Scharagrodsky (Coord.). Tras las huellas de la Educación Física Escolar Argentina. Cuerpo, género y pedagogía 1880-1950 (pp. 159-197). Buenos Aires: Prometeo.

Scharagrodsky, P. (2007). Masculinidades en acción: machos, maricas, subversivos y cómplices. El caso de la Educación Física argentina. En 
Swain, T. et. al. Corpo, genero e sexualidades. Discutindopráticas educativas. Rio Grande: Editora de FURG.

Scharagrodsky, P. (2011) La constitución de la educación física escolar en la Argentina. Tensiones, conflictos y disputas con la matriz militar en las primeras décadas del siglo XX. En Scharagrodsky, P. (Comp.). La invención del "homo gymnasticus: Fragmentos históricos sobre la educación de los cuerpos en movimiento en Occidente. Buenos Aires: Prometeo.

Scharagrodsky, P. (2019). Notas sobre los lugares en la Educación y la Educación Física, Argentina, finales del siglo XIX y principios del XX. Materiales para la historia del deporte. $\mathrm{n}^{\circ} 18$, pp.73-87. https://www.upo.es/revistas/inde x.php/materiales_historia_deporte/article/view/3458

Serra, M. (2019). Pedagogía + arquitectura: reflexiones acerca del cruce de disciplinas. Anuario de Historia de la Educación. Vol 20, n1, pp. 107-123. http://ppct.caicyt.gov.ar/index.php/anuario/article/view/15603

Soprano Manzo, G. (2009). Autonomía universitaria e intervención política en la trayectoria de liderazgos y grupos académicos en Ciencias Naturales de la Universidad Nacional de La Plata 1930-1955. Anuario del Instituto de Historia, n9, pp. 97-147. http://sedici.unlp.edu.ar/handle/10915/12436

Stake, R. (2005). La investigación con estudios de casos. Madrid: Ediciones Morata.

Tarrés, M. (2013). A propósito de la categoría género: leer a Joan Scott. Estudios Sociológicos, vol. XXXI, núm. 91, enero-abril, 2013, pp. 3-26. https://dial net.unirioja.es $/$ servlet $/$ articulo?codigo $=6164482$

Tedesco, J. (1993). Educación y Sociedad en la Argentina (1880-1945). Buenos Aires: Solar.

Tófoli, M. (2016). Género y trabajo: la operación de "lopúblico" y "loprivado" en la cotidianeidad laboral de las mujeres. [ponencia] IX Jornadas de Sociología de la UNLP, 5 al 7 de diciembre de 2016, Argentina. http://www.memor ia.fahce.unlp.edu.ar/trab_eventos/ev.9153/ev.9153.pdf

Tubert, S. (2010). Los ideales culturales de la feminidad y sus efectos sobre el cuerpo de las mujeres. Quaderns de Psicologia, vol. 12, n2, pp. 161-174. ht tps://www.quadernsdepsicologia.cat/article/view/760

Universidad Nacional de La Plata (1929). Resolución de creación del Departamento de Cultura Física n444, 7 de marzo de 1929.

Universidad Nacional de La Plata (1947). Plan estructurado de actividades de la Dirección General de Educación Física dependiente de la Universidad Nacional de La Plata. La Plata.

Valera, S. (1999). Espacio privado, espacio público: Dialécticas urbanas y construcción de significados. Tres al Cuarto, 6, pp.22-24. http://www.ub .edu/escult/editions/0tresal.pdf

Vallejo, G. (2007). Escenarios de la cultura fisica argentina. Ciudad y universidad (1882-1955). Madrid: Consejo Superior de Investigaciones Científicas.

Vallejo, G. (2018). José Gabriel: un emergente de la nueva generación argentina en tiempos de la Reforma Universitaria (1920-1932). Questionesde ruptura; vol. 2, pp. 48 - 70

Valobra, A. (2010). La ciudadanía política femenina en la Argentina de la primera mitad de siglo XX: Aportes para una aproximación conceptual y recursos didácticos. Clío y Asociados, 14, pp. 86-112. http://www.memor ia.fahce.unlp.edu.ar/art_revistas/pr.4022/pr.4022.pdf 
Villa, A. (2011). Distinción y destino. Aportes de la educación a la construcción social de los privilegios: El caso de las familias tradicionales platenses (tesis doctoral). Universidad Nacional de La Plata, La Plata.

Viñao Frago, A. (1993-1994). Del espacio escolar y la escuela como lugar: propuestas y cuestiones. Historia de la Educación: Revista interuniversitaria. $\mathrm{N}^{\circ} 12-13$, pp. 17-74. https://revistas.usal.es/index.php /0212-0267/article/view/11367

Viñao Frago, A. (2008). Escolarización, edificios y espacios escolares. Participación educativa, vol. 7, pp. 16-27. https://m.redined.mecd.gob.es/xmlui/bitstream/handle/11162/ 91607/00820113013998.pdf? sequence $=1$

Zeballos de Heredia, C. (1930). Memoria del Colegio Secundario de Señoritas. Universidad Nacional de La Plata.

\section{Notas}

1 Este trabajo es resultado de mi tesis doctoral en Ciencias de la Educación (Universidad Nacional de La Plata), en curso, que aborda el Departamento de Cultura Física de la Universidad Nacional de La Plata (1929-1946) desde una perspectiva de género. La investigación cuenta con el apoyo de una beca doctoral CONICET (con lugar de trabajo en el IDIHCS) y es dirigida por el Dr. Pablo Scharagrodsky y codirigida por el Dr. Martín Legarralde.

2 Ramón Godofredo Loyarte (1888-1944). Físico argentino, doctorado en Química, que estudió en la UNLP y en Gottigen (Alemania). Fue presidente de la Universidad entre 1927 y 1930 , y en 1932. Esta personalidad, en la esfera de la política nacional, fue elegido como diputado en el año 1932, ocupando su banca hasta 1934, por el "Partido Demócrata Nacional" o "Conservador", formado sobre la base de partidos conservadores provinciales, liderado por dirigentes como Julio Argentino Roca (hijo) y Manuel Fresco. Se trató de un partido de derecha que se construyó según el modelo del viejo Partido Autonomista Nacional, que gobernó el país durante más de una década, en una alianza con sectores radicales y socialistas conocida como Concordancia. En 1943 fue designado interventor del Consejo Nacional de Educación.

3 Rafael Alberto Arrieta (1889-1968) fue un poeta y crítico argentino. Estudió Letras en la Universidad de Buenos Aires y en la Universidad Nacional de La Plata. Fue profesor de Letras y Decano del CN (1928-1932). Su poesía es heredera de la corriente modernista fundada por Rubén Darío.

4 Benigno Rodríguez Jurado (1894-1959). Nació en la provincia de San Luis, donde su padre fue gobernador. No habría contado con un título docente, por lo que su reputación la habría forjado a partir de una exitosa carrera deportiva. Ocupó cargos directivos en el Club Universitario de Buenos Aires, fue Director del DCF en los 18 años de su existencia, y fue la máxima autoridad de la Dirección General de Educación Física y Cultura de la provincia de Buenos Aires entre 1940 y 1952.

5 Para profundizar la adhesión del DCF al discurso médico, véase Kopelovich (2019). Para indagar en la comparación de los discursos legitimantes del DCF y de la Dirección General de Educación Física de la UNLP, véase Kopelovich (2020).

6 Destacamos aquí el mito del instinto materno (Badinter, 1993).

7 Estuvo al frente del colegio entre 1923 y 1934.

8 El CSS se mudó en 1931 a un edificio ubicado en las calles diagonal 77 y 5 (La Plata).

9 Se desempeña en el Colegio desde 1909. Comienza siendo practicante de botánica, convirtiéndose posteriormente en profesora. Fue directora entre 1934 y 1939. Se recibió de farmacéutica y profesora de enseñanza secundaria 
en historia natural y química. También fue docente de práctica pedagógica de Mineralogía y Geología en la Facultad de Humanidades y Ciencias de la Educación. En 1927 se doctoró en Química con una tesis sobre resinas fósiles. Por esos años, realizó varias estadías de investigación en la Universidad de Heidelberg, algo poco frecuente entre las naturalistas de esa época (García, 2011). Germán Soprano (2009) al estudiar liderazgos y grupos académicos en Ciencias Naturales de la UNLP entre 1930 y 1945 la menciona como una figura clave. Alicia Villa (2011) menciona a la familia Cortelezzi entre las primeras familias de la ciudad que contaba con personalidades de la educación y la cultura.

10 Agradezco al profesor Nicolás Patierno el haberme facilitado el contacto para la realización de las dos entrevistas.

11 Agradezco al profesor Santiago Fusé el haberme facilitado el contacto para la realización de esas dos entrevistas.

12 Agradezco al Dr. Gustavo Vallejo el haber compartido esta información. 